\title{
Intra Nasal Midazolam vs. Rectal Diazepam in Management of Acute Sei- zures in Pediatrics, Considering the Antiepileptic Drugs Monitoring
}

\author{
JIAN JIAO, XINLU ZUO*, NA LIU, JI WANG, AIDONG ZHANG AND BOWE QIN \\ Department of Foreign Nursing, Chengde Nursing Vocational College, Chengde, 067000, China
}

Jiao et al.: Intra Nasal Midazolam vs. Rectal Diazepam for Acute Seizures in Pediatrics

\begin{abstract}
Immediate management of children's epilepsy is essential before the patient arrives to the hospital. The purpose of this study was to compare the efficacy of intranasal midazolam vs. rectal diazepam in the management of acute pediatric seizures. In this cross-sectional study, 68 patients having acute seizure were evaluated for response to treatment after receiving intra-nasal midazolam (34 patients) or rectal diazepam (34 patients). Patents were assessed by physicians at the arrival to emergency department for history taking and examination. Blood samples were assessed for valproate, phenobarbital and phenytoin levels in serum to determine previous use of antiepileptic drugs. Seizure duration and response time to treatment were evaluated along with health care utilization and were compared between study groups, by the statistical package for the social sciences software. Mean age of study participants, sex disturbance, age at onset of a seizure, type of seizure and prehospital time had not any significant differences between two groups $(p>0.05)$. The mean response time to diazepam was $8.0 \pm 4.9 \mathrm{~min}$ and $6.3 \pm 2.2 \mathrm{~min}$ for midazolam; which had a significant difference between groups $(0.001)$. Linear regression of serum antiepileptic drug levels in association of response time in each group was not significant in all case $(p>0.05)$, expect the lamotrigine serum level in midazolam group $(\mathrm{p}=\mathbf{0 . 0 2 9})$. Intranasal midazolam was seen to have a better effect than rectal diazepam in the management and treatment of acute seizures in children; while antiepileptic drugs monitoring want helpful in assessing the absolute effect.
\end{abstract}

Key words: Intranasal midazolam, intranasal diazepam, acute seizures, antiepileptic drugs monitoring, children

Seizures are a common neurological disorder in the pediatric age group ${ }^{[1]}$. The prevalence of this disease is $2-5 \%$ and indicates a major disorder in the central nervous system ${ }^{[2,3]}$. Since 10-20\% of children with epilepsy are still suffering from acute epileptic seizures despite receiving a variety of Antiepileptic drugs (AEDs), immediate management of these attacks would be necessary. Managing acute seizure should be started out of hospital and in the case of delayed treatment, the chance of successful response to single drug therapy would be reduced ${ }^{[3]}$. Therefore, rapid control of seizures by the patient's relatives can be beneficial and result in less drug use in hospital and shorter duration of seizures ${ }^{[4]}$. Most cases of rectal diazepam are used for treatment before the patient arrives to emergency department, but there are drawbacks ${ }^{[5]}$. Firstly, the maximum plasma concentration of diazepam, obtained after rectal administration would be achieved 2 to $5 \mathrm{~min}$ later $^{[6]}$, due to slow absorption and low bioavailability of rectal diazepam ${ }^{[4,6]}$. Secondly, low bioavailability makes the clinical response in different individuals considerably different ${ }^{[7]}$. Midazolam is the a water soluble benzodiazepine with a half-life of less than diazepam ${ }^{[3]}$. Midazolam could be used in intravenous, intramuscular, intranasal and rectal route ${ }^{[8]}$. An efficient AED should cause less complications and has a good effect in seizure contro ${ }^{[9]}$. After intranasal administration of midazolam, the maximum plasma concentration can be accessed within 4-5 min. This route of midazolam administration increases the activity of beta waves in electroencephalography (EEG) ${ }^{[10]}$. By administering it through the nose, by eliminating the need for first passage of the liver, it will be absorbed rapidly and directly into the systemic circulation, while being a non-invasive procedure ${ }^{[11]}$. As more patients are using AEDs to control epilepsy, judgment about the failure or success of treatment by a single drug in randomized clinical trial would not be possible without determination

*Address for correspondence

E-mail: zuoxinlu@126.com 
of blood levels of these drugs. Due to the conflicts of previous studies, the aim of this study was to compare the efficacy of rectal diazepam and nasal midazolam in the control of acute pediatric seizures, along with monitoring blood AEDs level. This cross sectional descriptive study lasted from March 2019 to May 2019. The study was conducted on the pediatric ward of affiliated Hospital to Jiamusi University. Study was approved by committee of ethics in research of Jiamusi University. A previous clinical trial study by Lather et al. demonstrated the efficacy for control of seizure episode in the midazolam group and the diazepam group to be approximately $92.3 \%$ and $65 \%$, respectively. Considering this factor, it was calculated that at least 34 patients were required to be enrolled in each group (Alpha $=0.05$, Beta $=0.2$, Power $=0.8$ ). In this study, 68 patients with acute seizures were enrolled. Patients who had not received any treatment by parents before the hospital were included in the study. The same number of packed equivalent envelopes containing the name of the drug to be delivered was randomly distributed. In the pediatric ward, a box containing such envelopes was held. When an individual was enrolled in the research, randomization was done by selecting an envelope to either group and the specified drug was prescribed $^{[12]}$. There were two types of envelopes containing nasal spray of midazolam $0.2 \mathrm{mg} / \mathrm{kg}$ body weight and $0.3 \mathrm{mg} / \mathrm{kg}$ body weight rectal diazepam. With the help of a nasal spray, midazolam was inserted into the anterior nares and diazepam was inserted into the rectum with an 8-F size infant feeding tube inserted into the anal opening for $4 \mathrm{~cm}$. The time of entry to emergency department (ED) and stop of seizure was recorded. Patients were given continuous pulse oximetry. Patients were monitored for complications such as tachycardia, bradycardia, hypotension, bradypnea, shortness of breath, arterial oxygen saturation for up to $1 \mathrm{~h}$ in the ED and then for $4 \mathrm{~h}$ in the next transferred ward. We considered the efficacy of the drug as the time of seizure stop. At the patient arrival 2 cc blood sample was taken. AEDs monitoring methods were done using High-performance liquid chromatography-Ultraviolet (HPLC-UV)/Liquid chromatography-mass spectrometry (LC-MS) methods ${ }^{[13]}$. All data collected were entered in the Microsoft Excel (MS Excel). Data were analyzed using Statistical Package for Social Sciences (SPSS) 15.0 version. All categorical variables were expressed in numbers (percentage) and all continuous variables were expressed as mean standard deviation (SD) or median (IQR). Categorical variables were compared using Chi-
Square Test or Fischer Exact test. Continuous variables were compared between the midazolam group and diazepam group using Student's' $t$ ' test or Wilcoxon Rank Sum test. All tests were two-tailed and $\mathrm{p}<0.05$ was considered to be statistically significant. 68 participants were enrolled in this study. Mean age of participants in midazolam group $(4.8 \pm 1.1 \mathrm{y})$ had not significant difference with Diazepam group (4.5 $\pm 1.7 \mathrm{y}$ ). There were 13 male individuals in midazolam group and 17 in diazepam group, with no significant difference in distribution based on the subject's gender $(\mathrm{p}>0.05)$. Generalized tonic, generalized tonic-colonic and Focal seizures happened in 26.47, 38.24, and $35.29 \%$ of midazolam group and $38.24,38.24$, and $23.53 \%$ of diazepam group, without any significant difference of distribution of type of seizure $(\mathrm{p}>0.05)$. As shown in Table 1, demographic and clinical characteristics of children with epilepsy who have used intranasal midazolam or rectal diazepam, had not any significant difference, in case of frequency of seizures, age at onset of seizures in months, duration of seizures, being febrile or not, history of previous seizures and pre-hospital coma score $(p>0.05)$. The timing of seizures per minute in each group is given in fig. 1 . The analysis of the two groups revealed that the mean response time to diazepam (39.2 \pm 13.2$)$ and mean response time of midazolam (48.5 \pm 15.4$)$ had a significant difference $(p=0.001)$. There was no significant difference between the two groups regarding the total pre-hospital time $(\mathrm{p}>0.05)$. There was no significant difference between the two groups regarding the seizure duration $(\mathrm{p}>0.05)$. As shown in Table 2, median serum level of study subjects was demonstrated as possible conflicting factor which this issue was assessed by linear regression. Linear Regression of serum AED levels in association of response time in each group was not significant in all case $(p>0.05)$, expect the lamotrigine serum level in midazolam group $(p=0.029)$. The pharmacological effects of midazolam are similar to those of other benzodiazepines and include: hypnotic, sedative, anticonvulsant, muscle relaxant and stress relievers ${ }^{[14]}$. The difference between midazolam and other AEDs is the faster onset of activity and a shorter duration of activity $^{[15]}$. Midazolam belongs to a more potent drug group than benzodiazepines called imidazobenzodiazepines ${ }^{[8]}$. Yoshikawa et al. showed that midazolam as a first-line drug is effective in treating childhood static seizures ${ }^{[20]}$. At an acidic $\mathrm{pH}$ of less than 2, the benzapine ring opens up the drug and increases its solubility in water ${ }^{[8]}$. At physiological $\mathrm{pH}$, the benzepine ring is tightened, causing the drug's 
lipophilicity, which increases the speed of molecules to pass through the nasal mucosa and blood-brain barrier ${ }^{[16]}$. On the other hand, it has been shown that midazolam tends to bind to benzodiazepine receptors in the central nervous system. Therefore, in addition to speed, its effect will be greater than diazepam. Mucosal administration of midazolam results in a rapid increase in plasma and cerebrospinal fluid(CSF) concentrations ${ }^{[17]}$ (Table 3). De Haan et al.[18] performed the effect of nasal spray midazolam and rectal diazepam solution on the treatment of seizures in adults. Their results showed that there was no difference in the onset of the anticonvulsant effect of the drugs studied. This is inconsistent with the results of our study. This difference can be attributed to the age of the study group. In a prospective study conducted by Fişgin et al. ${ }^{[19]}$ as an anticonvulsant, intranasal midazolam ${ }^{[20]}$ is more effective than rectal diazepam, although this requires further research. They found no serious complications in their study. Lahat et al. ${ }^{[21]}$ compared the effects of intranasal midazolam with intravenous diazepam in controlling febrile convulsions. At the end, it was concluded that although intravenous diazepam works faster than intranasal midazolam, the time spent on intravenous administration may eventually lead to a decrease in seizures in the intravenous diazepam receiving group. And, therefore, nosebleeds are preferred even in emergency cases. This study was limited to cases of fever and seizures and was not compared with rectal diazepam. In another study, Scott et al. compared oral midazolam to rectal diazepam in pediatric seizure control and stated that oral medial midazolam was at least as effective and moderately effective as diazepam. In this study, intermittent periods of seizures were reported in both groups about 1 to 5 min ${ }^{[22]}$. The delayed effect of intraoral midazolam appears to be due to its delayed absorption from the large oral cavity space and the narrowing of the oral vessels (as compared to the small space and rich nasal cavity vessels). In our study, the efficacy of nasal administration of midazolam in controlling acute seizures in children was more than rectal diazepam. The mean response to treatment with midazolam was less than diazepam; while the duration of seizure had not any difference which could be due to timing of medication prescription or individual changes. Bhattacharyya et al. in a similar study of 188 seizures in 46 children also found that nasal administration of midazolam was preferable to the treatment of pediatric seizures through rectal diazepam ${ }^{[23]}$. Monitoring AEDs in our study didn't reveal any significant information; while a significant association was seen in the case of lamotriginem which had not a high power. This analysis was done to show that the occurred response was just due to the prescribed medications. Finally, according to the results of the present study, midazolam can replace intranasal diazepam by nasal route and can provide better results if it is properly taught to the family. Larger studies, however, are needed with more children and evaluating the effect of seizures types. Therefore, intranasal midazolam may not be able to replace rectal diazepam in the control of acute pediatric seizures outside the hospital. Especially if midazolam products would be available in the form of a spray or a nasal drip, easier use and greater efficacy of the drug will be expected.

TABLE 1: DEMOGRAPHIC AND CLINICAL CHARACTERISTICS OF CHILDREN WITH EPILEPSY

\begin{tabular}{|c|c|c|c|c|}
\hline variable & & Midazolam group & Diazepam group & $\mathrm{p}$ \\
\hline $\mathrm{n}$ & & 34 & 34 & - \\
\hline \multirow[t]{2}{*}{ Age, years $($ mean $\pm S D)$} & & $4.8 \pm 1.1$ & $4.5 \pm 1.7$ & 0.411 \\
\hline & male & $13(38.24)$ & $17(50)$ & \\
\hline \multirow[t]{3}{*}{ Sex, n (\%) } & Female & $21(61.76)$ & $17(50)$ & 0.169 \\
\hline & Generalized tonic & $9(26.47)$ & $13(38.24)$ & \\
\hline & $\begin{array}{l}\text { Generalized tonic- } \\
\text { colonic }\end{array}$ & $13(38.24)$ & $13(38.24)$ & \\
\hline \multirow[t]{3}{*}{ Type of seizure, n (\%) } & Focal seizures & $12(35.29)$ & $8(23.53)$ & 0.935 \\
\hline & Daily & $6(17.65)$ & $6(17.65)$ & \\
\hline & Weekly & $5(14.71)$ & $6(17.65)$ & \\
\hline
\end{tabular}




\begin{tabular}{|c|c|c|c|c|}
\hline \multirow{3}{*}{$\begin{array}{l}\text { Frequency of seizure, } \\
n(\%)\end{array}$} & Monthly & $10(29.41)$ & $6(17.65)$ & \multirow{3}{*}{0.327} \\
\hline & Six monthlies & $8(23.53)$ & $9(26.47)$ & \\
\hline & Yearly & $5(14.71)$ & $7(20.59)$ & \\
\hline \multicolumn{2}{|c|}{ Age at onset of a seizure in months, months } & $40.8 \pm 17.1$ & $37.05 \pm 15.2$ & 0.453 \\
\hline \multicolumn{2}{|l|}{ History of fever, n (\%) } & $17(50)$ & $13(38.24)$ & 0.169 \\
\hline \multicolumn{2}{|c|}{$\begin{array}{l}\text { Pre-hospital Glasgow Coma Scale score } \\
(\text { mean } \pm \text { SD) }\end{array}$} & $8.6 \pm 1.09$ & $8.5 \pm 1.2$ & 0.123 \\
\hline \multirow{5}{*}{ Condition of child } & Normal & $9(\%$ 26.47) & $8(\% 23.53)$ & \multirow{5}{*}{0.725} \\
\hline & Seizing & $8(\% 23.53)$ & $8(\% 23.53)$ & \\
\hline & Unconscious & $6(\%$ 17.65) & $10(\% 29.41)$ & \\
\hline & Not known & $5(\%$ 14.71) & $5(\%$ 14.71) & \\
\hline & Not presented to ED & $6(\%$ 17.65) & $3(\% 8.8)$ & \\
\hline
\end{tabular}

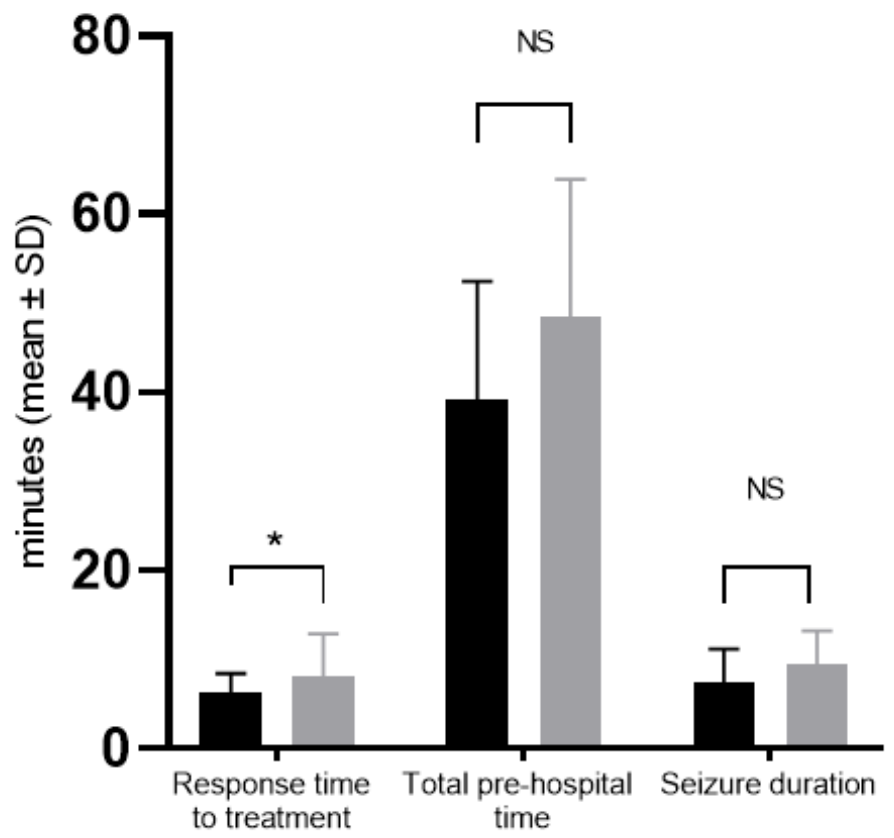

Fig. 1: Response time, total pre-hospital time and seizure duration *significant difference between groups, $\mathbf{p}<0.05$; NS: not significant difference,

TABLE 2: AEDS MONITORING RESULTS, SERUM LEVEL WITH MEDIAN (IQR)

\begin{tabular}{lcc}
\hline Group & Midazolam Group & Diazepam Group \\
\hline Valproate, $\mu \mathrm{g} / \mathrm{m}$ & $0(0-18.7225)$ & $9.275(0-23.9275)$ \\
Phenobarbital, $\mu \mathrm{g} / \mathrm{m}$ & $1.68(0-25.1975)$ & $1.15(0-31.9675)$ \\
Phenytoin, $\mu \mathrm{g} / \mathrm{m}$ & $0.98(0-14.9)$ & $0(0-17.005)$ \\
Levetiracetam, $\mathrm{g} / \mathrm{m}$ & $0(0-2.2)$ & $0(0-3.5)$ \\
Lamotrigine, $\mu \mathrm{g} / \mathrm{m}$ & $0(0-0)$ & $0(0-0)$ \\
Felbamate, $\mu \mathrm{g} / \mathrm{m}$ & $0(0-0)$ & $0(0-0)$ \\
Primidone, $\mu \mathrm{g} / \mathrm{m}$ & $0(0-0)$ & $0(0-0.0225)$ \\
Ethosuximide, $\mu \mathrm{g} / \mathrm{m}$ & $0(0-0)$ & $0(0-0)$ \\
Lacosamide, $\mu \mathrm{g} / \mathrm{L}$ & $0(0-0)$ & $0(0-0.0375)$ \\
Gabapentin, $\mu \mathrm{g} / \mathrm{m}$ & $0(0-0.6075)$ & $0(0-2.685)$
\end{tabular}


www.ijpsonline.com

TABLE 3: LINEAR REGRESSION OF SERUM AED LEVELS IN ASSOCIATION OF RESPONSE TIME (SEIZURE STOP TIME)

\begin{tabular}{lcccccc}
\hline & \multicolumn{3}{c}{ Midazolam Group } & \multicolumn{3}{c}{ Diazepam Group } \\
\cline { 2 - 6 } & Coefficient & Standard error & $\mathrm{p}$ & Coefficient & Standard error & $\mathrm{p}$ \\
\hline Valproate, $\mu \mathrm{g} / \mathrm{m}$ & 0.018 & 0.032 & 0.573 & 0.022 & 0.064 & 0.738 \\
Phenobarbital, $\mu \mathrm{g} / \mathrm{m}$ & -0.004 & 0.027 & 0.886 & 0.078 & 0.047 & 0.109 \\
Phenytoin, $\mu \mathrm{g} / \mathrm{m}$ & 0.03 & 0.033 & 0.376 & -0.044 & 0.063 & 0.485 \\
Levetiracetam, $\mu \mathrm{g} / \mathrm{m}$ & -0.028 & 0.038 & 0.460 & 0.099 & 0.099 & 0.653 \\
Lamotrigine, $\mu \mathrm{g} / \mathrm{m}$ & -0.316 & 0.137 & 0.029 & 0.438 & 0.438 & 0.734 \\
Felbamate, $\mu \mathrm{g} / \mathrm{m}$ & -0.022 & 0.045 & 0.628 & 0.096 & 0.096 & 0.158 \\
Primidone, $\mu \mathrm{g} / \mathrm{m}$ & -0.071 & 0.181 & 0.698 & 0.667 & 0.667 & 0.809 \\
Ethosuximide, $\mu \mathrm{g} / \mathrm{m}$ & -0.008 & 0.021 & 0.700 & 0.038 & 0.038 & 0.137 \\
Lacosamide, $\mathrm{mg} / \mathrm{L}$ & -0.047 & 0.075 & 0.535 & 0.170 & 0.170 & 0.528 \\
Gabapentin, $\mu \mathrm{g} / \mathrm{m}$ & 0.211 & 0.231 & 0.370 & 0.425 & 0.425 & 0.794 \\
Valproate, $\mu \mathrm{g} / \mathrm{m}$ & -0.028 & 0.038 & 0.460 & 0.099 & 0.099 & 0.653 \\
\hline
\end{tabular}

\section{Acknowledgement:}

Title of scientific research project of Heilongjiang Provincial Health and Construction Commission: Study on the protective effect of levetiracetam on the midbrain of epileptic young rats (Project No: 2018223).

\section{Conflict of Interests:}

The authors have declared no conflict of interests.

\section{REFERENCES}

1. Mahmoudian T, Zadeh MM. Comparison of intranasal midazolam with intravenous diazepam for treating acute seizures in children. Epilepsy Behav 2004;5(2):253-5.

2. Hauser WA. The prevalence and incidence of convulsive disorders in children. Epilepsia 1994;35:S1-6.

3. Holsti M, Sill BL, Firth SD, Filloux FM, Joyce SM, Furnival RA. Prehospital intranasal midazolam for the treatment of pediatric seizures. Pediatr Emerg Care 2007;22(3):148-53.

4. Scott RC, Besag FM, Neville BG. Buccal midazolam and rectal diazepam for treatment of prolonged seizures in childhood and adolescence: a randomised trial. Lancet 1999;353(9153):6236.

5. Baysun Ş, Aydin ÖF, Atmaca E, Gürer YY. A comparison of buccal midazolam and rectal diazepam for the acute treatment of seizures. Clin Pediatr 2005;44(9):771-6.

6. Thakker A, Shanbag P. A randomized controlled trial of intranasal-midazolam versus intravenous-diazepam for acute childhood seizures. J Neurol 2013;260(2):470-4.

7. Orr RA, Dimand RJ, Venkataraman ST, Karr VA, Kennedy KJ. Diazepam and intubation in emergency treatment of seizures in children. Ann Emerg Med 1991;20(9):1009-13.

8. Nordt SP, Clark RF. Midazolam: a review of therapeutic uses and toxicity. J Emerg Med 1997;15(3):357-65.

9. Schmitz B. Effects of antiepileptic drugs on mood and behavior. Epilepsia 2006;47:28-33.
10. Lindhardt K, Gizurarson S, Stefánsson SB, Òlafsson DR, Bechgaard E. Electroencephalographic effects and serum concentrations after intranasal and intravenous administration of diazepam to healthy volunteers. $\mathrm{Br} \mathrm{J}$ Clin Pharmacol 2001;52(5):521-7.

11. Misra A, Jogani V, Jinturkar K, Vyas T. Recent patents review on intranasal administration for CNS drug delivery. Recent Pat Drug Deliv Formul 2008;2(1):25-40.

12. Bhattacharyya $\mathrm{M}$, Kalra $\mathrm{V}$, Gulati S. Intranasal midazolam vs rectal diazepam in acute childhood seizures. Pediatr Neurol 2006;34(5):355-9.

13. Kang J, Park YS, Kim SH, Kim SH, Jun MY. Modern methods for analysis of antiepileptic drugs in the biological fluids for pharmacokinetics, bioequivalence and therapeutic drug monitoring. Korean J Physiol Pharmacol 2011;15(2):67.

14. Blumer JL. Clinical pharmacology of midazolam in infants and children. Clin Pharmacokinet 1998;35(1):37-47.

15. Nauta J, Stanley TH, de Lange S, Koopman D, Spierdijk J, van Kleef J. Anaesthetic induction with alfentanil: comparison with thiopental, midazolam, and etomidate. Can Anaesth Soc J 1983;30(1):53-60.

16. Galley HF, Dubbels AM, Webster NR. The effect of midazolam and propofol on interleukin-8 from human polymorphonuclear leukocytes. Anesth Analg 1998;86(6):1289-93.

17. Dhir A, Zolkowska D, Rogawski MA. Seizure protection by intrapulmonary delivery of midazolam in mice. Neuripharma $2013 ; 73: 425-31$.

18. De Haan GJ, Van Der Geest P, Doelman G, Bertram E, Edelbroek P. A comparison of midazolam nasal spray and diazepam rectal solution for the residential treatment of seizure exacerbations. Epilepsia 2010;51(3):478-82.

19. Fişgin T, Gurer Y, Tezic T, Senbil N, Zorlu P, Okuyaz C, et al. Effects of intranasal midazolam and rectal diazepam on acute convulsions in children: prospective randomized study. J Child Neurol 2002; 17(2):123-6.

20. Yoshikawa H, Yamazaki S, Abe T, Oda Y. Midazolam as a first-line agent for status epilepticus in children. Brain Dev 2000;22(4):239-42. 
21. Lahat E, Goldman M, Barr J, Bistritzer T, Berkovitch M. Comparison of intranasal midazolam with intravenous diazepam for treating febrile seizures in children: prospective randomised study. BMJ 2000;321(7253):83-6.

22. Scott RC, Besag FM, Neville BG. Buccal midazolam and rectal diazepam for treatment of prolonged seizures in childhood and adolescence: a randomised trial. Lancet 1999;353(9153):623-6.

23. Bhattacharyya M, Kalra V, Gulati S. Intranasal midazolam vs. rectal diazepam in acute childhood seizures. Pediatr Neurol 2006;34(5):355-9.
This is an open access article distributed under the terms of the Creative Commons Attribution-NonCommercial-ShareAlike 3.0 License, which allows others to remix, tweak, and build upon the work non-commercially, as long as the author is credited and the new creations are licensed under the identical terms

This article was originally published in a special issue,

"Trends in Therapeutic Management of Various Clinical

Conditions II" Indian J Pharm Sci 2021:83(2)Spl issue;184-189 